\title{
US researchers push network of massive spectrometers
}

[WASHINGTON] An ambitious plan for ten regional 'collaboratories', each equipped with powerful nuclear magnetic resonance (NMR) spectrometers, has been proposed by an informal group of US scientists. The move is based on the belief that high-field NMR is set to emerge as a critical research tool for structural biologists, geneticists and materials scientists.

The group, led by the National High Magnetic Field Laboratory at Florida State University at Tallahassee, suggests that the US government should spend $\$ 110$ million on establishing the new centres and equipping them with spectrometers that can measure proton resonance at $900 \mathrm{Mhz}$.

A further $\$ 150$ million would be spent later to provide even better spectrometers that could operate at $1 \mathrm{GHz}$, a higher performance than is currently obtained by any actual or planned NMR machine.

NMR spectrometers, which can determine the structure of molecules that cannot be synthesized as single crystals for observation by the more established means of X-ray crystallography, improve in resolution as the cube of their operating frequency. Incremental increases in frequency therefore greatly increase their usefulness, advocates of the approach point out.

But the powerful superconducting magnets that drive NMR spectrometers are difficult to build because of the immense stresses to which they are subjected as the frequency of the machines is raised.

An order for what would be the most powerful NMR spectrometer in the world a $900-\mathrm{MHz}$ machine to be installed at the Department of Energy's Pacific Northwest National Laboratory (PNNL) in Washington

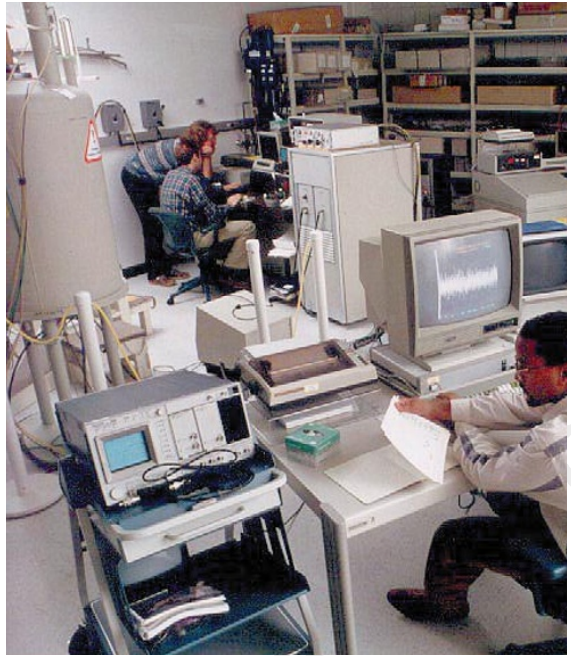

A matter of size: larger machines may be needed than those available in individual labs (above).

State - is running two years late.

US sources say the contractor, UK-based Oxford Instruments, has lost money on the $\$ 7$ million order, and replaced the head of its NMR unit earlier this year as a result of problems in delivering the order. The new head of the unit, Alan Street, says the magnet will undergo a new round of testing this week, and that it should be delivered next summer.

These technical problems, together with what agency officials describe as a narrow base of support for NMR spectroscopy among the scientific disciplines to which it should be of most value, means that the proposal for ten regional centres has been met with scepticism in Washington.

But Jack Crow, director of the Tallahassee laboratory, says the time is right for the government to plan a series of national centres to

\section{Climate conference agrees action plan}

[LONDON] The fourth conference of the parties to the United Nations climate convention ended in Buenos Aires last week, with agreement on a plan of action and a deadline of the year 2000 to finalize mechanisms for implementing the Kyoto protocol.

These include mechanisms for trading of greenhouse-gas emissions between developed countries, help for developing countries with clean energy projects, funding on technology transfer, and help from the global environment facility for countries adapting to climate change.

The United States, which last week became the sixtieth country to sign the
Kyoto protocol, made some progress in its attempts to make developing countries undertake voluntary commitments to reduce greenhouse-gas emissions.

The Group of 77 countries prevented this issue from becoming a formal agenda item. Argentina, followed by Kazakhastan, from breaking ranks and agreeing voluntary commitments to reduce emissions.

The protocol will not become legally binding until 55 per cent of developed and developing countries sign the protocol and ratify it in their national parliaments. So far, this has been done in just two countries: Fiji, and Antigua and Barbuda. Ehsan Masood But it failed to prevent the host country, meet future scientific needs. He compares the current status of NMR to the earlier evolution of X-ray spectroscopy, when scientists switched from inexpensive equipment at their own university departments to the far more powerful synchrotrons at central government-run facilities.

Many university departments have NMR spectrometers that operate at 300 or 400 $\mathrm{MHz}$, says Crow, and some can afford 750Mhz machines. Spectrometers of $900 \mathrm{MHz}$ or more will be too expensive and complex for single universities to operate, he says, but scientists will still want access to them.

According to the report, the larger machines will allow biologists to solve the structures of proteins with molecular weight of 100,000 dalton, twice today's upper limit. They would also generate new structures more rapidly, it says.

Crow and 20 other NMR specialists produced a report outlining their proposal in August, at the suggestion of the National Science Foundation (NSF). The report says that the 'collaboratorium' - a US term describing centres whose participants communicate over high-speed Internet links - would be the best way to distribute access to the spectrometers, which would themselves be distributed across the United States.

The report also argues that more powerful NMR machines will benefit materials scientists, and would enable biologists to solve the problems of structure needed to improve understanding of gene function and regulation, as well as issues in neuroscience. But agency officials remain to be convinced that an expensive network of state-of-the-art facilities is justified at this stage.

The "case has not yet been made" for the network, says Robert Eisenstein, head of the mathematical and physical sciences directorate at the NSF. NMR facilities that can operate at $1 \mathrm{GHz}$ "will be needed at some point, but not today", says Mary Clutter, head of biological sciences at the foundation.

Others are more upbeat. Marvin Cassman, director of the National Institute of General Medical Sciences at the National Institutes of Health, says the value of NMR spectroscopy will increase as the available field increases, and that he supports further discussion of the proposal.

Ari Patrinos, head of biological and environmental sciences at the Department of Energy, says of the high-field NMR spectrometers: "I don't think they'll have as prominent a role as light sources, but they are an element of the panoply of tools that we'll use".

ColinMacilwain 